\title{
DISCOURSE FUNCTIONS OF DEMONSTRATIVES IN EASTERN BANTU NARRATIVE TEXTS
}

\author{
Steve Nicolle \\ Canada Institute of Linguistics and SIL International
}

\begin{abstract}
Demonstratives are an important feature of many eastern Bantu narrative texts. In addition to a basic tracking use, in which demonstratives are used to refer to different participants in a narrative, at least four additional functions can be identified: specifying the activation status (activated vs. reactivated) of major participants; distinguishing participants with agent semantic roles from those with non-agent semantic roles; distinguishing different kinds of participants and different episodes; and marking key thematic developments. These functions are described for 10 eastern Bantu languages based on analyses of original (i.e. non-translated) narrative texts.
\end{abstract}

\section{Introduction}

This paper ${ }^{1}$ describes the functions of demonstratives in narrative texts in 10 Bantu languages spoken in Mozambique, Tanzania, Kenya and the Democratic Republic of the Congo (collectively referred to here as 'eastern Bantu languages'). Demonstratives are common referential devices in narratives in these languages, but in addition to the basic function of identifying specific referents in a text, different demonstratives also operate at the level of the text as a whole - that is, they exhibit what will be called 'discourse-level' functions. Although the languages in this study are closely related, four distinct systems of discourse-level functions can be identified.

The paper is organized as follows: Section 2 details the languages and data sets used in this study, and describes the forms of cognate demonstratives in these languages. Discourse analytic notions relating to participants and episodes in narrative texts are introduced in section 3 . In section 4, the four discourse-level functions of demonstratives are described, and a summary of findings is provided in section 5 .

\section{Data}

2.1 Languages and texts. This study is based on data from the 10 eastern Bantu languages listed in Table 1. The majority of texts studied in each language are usually folk tales involving either human or animal characters, but at least one non-fiction text is included for each language. Each

1 This is an expanded version of a paper given at the $5^{\text {th }}$ International Conference on Bantu Languages, Paris, 12-15 June 2013. I am grateful to the following colleagues for sharing their data and descriptions of participant reference in narrative texts: Elizabeth Broomhall, Helen Eaton, Rhoda Leech, Shannon Ronit Odom, Allison Pyle, Holly Robinson, Oliver Stegen, Amanda Masatu, and Roger Van Otterloo. Thanks are also due to two anonymous SAL referees for their insightful comments. All remaining errors are mine alone. 
text corpus includes a mixture of oral texts (transcribed from recordings of oral production) and written texts. The final column of Table 1 indicates the main published sources from which data is drawn. All material relating to the languages in this study is taken from texts that were either published in these sources or used in their preparation; where additional (unpublished) texts have been made available to me by the author, this is indicated by an asterisk "*”, and in the case of Digo, I included an additional 5 unpublished texts. Examples are cited in the orthographies used in the published sources. ${ }^{2}$

Table 1: Languages included in this study

\begin{tabular}{|c|c|c|c|}
\hline Language & $\begin{array}{l}\text { Classification } \\
\text { and country }\end{array}$ & Data & Source \\
\hline Fuliiru & $\begin{array}{l}{[\mathrm{flr}] \mathrm{DJ} 63} \\
\text { D.R. Congo }\end{array}$ & $\begin{array}{l}11 \text { fictional narratives, plus one first person and one } \\
\text { third person factual narrative }(1,000 \text { clauses } \\
\text { approximately) }\end{array}$ & $\begin{array}{l}\text { Van Otterloo } \\
(2011 ; \text { In press })^{*}\end{array}$ \\
\hline Digo & $\begin{array}{l}{[\text { dig] E73 }} \\
\text { Kenya }\end{array}$ & $\begin{array}{l}6 \text { fictional narratives ( } 5 \text { lightly edited oral texts }{ }^{4} \text { and } \\
1 \text { written text) and } 1 \text { written factual first person } \\
\text { narrative ( } 864 \text { clauses) }\end{array}$ & Nicolle (In press) \\
\hline Jita & $\begin{array}{l}{[\mathrm{jit}] \mathrm{EJ} 25} \\
\text { Tanzania }\end{array}$ & $\begin{array}{l}10 \text { lightly edited oral texts: } 7 \text { fictional and } 3 \text { factual } \\
(1,096 \text { clauses })\end{array}$ & $\begin{array}{l}\text { Pyle \& Robinson } \\
\text { (In press)* }\end{array}$ \\
\hline Kwaya & $\begin{array}{l}[\mathrm{kya}]) \text { EJ251 } \\
\text { Tanzania }\end{array}$ & $\begin{array}{l}10 \text { lightly edited oral texts: } 7 \text { fictional and } 3 \text { factual } \\
\text { (1,015 clauses) }\end{array}$ & Odom (In press)* \\
\hline $\begin{array}{l}\text { Suba- } \\
\text { Simbiti }\end{array}$ & $\begin{array}{l}{[\mathrm{ssc}] \mathrm{EJ} 403} \\
\text { Tanzania }\end{array}$ & $\begin{array}{l}8 \text { lightly edited oral texts: } 4 \text { fictional, } 2 \text { factual, and } 2 \\
\text { origin myths ( } 513 \text { clauses) }\end{array}$ & Masatu (In press)* \\
\hline Kabwa & $\begin{array}{l}\text { [cwa] EJ405 } \\
\text { Tanzania }\end{array}$ & $\begin{array}{l}9 \text { lightly edited oral texts and } 2 \text { written texts; } 8 \\
\text { fictional and } 3 \text { factual ( } 530 \text { clauses) }\end{array}$ & Higgins (2010)* \\
\hline $\begin{array}{l}\text { Rangi } \\
\text { (Langi) }\end{array}$ & $\begin{array}{l}{[\operatorname{lag}] \text { F33 }} \\
\text { Tanzania }\end{array}$ & $\begin{array}{l}66 \text { texts: } 32 \text { legends/anecdotes, } 14 \text { trickster tales, } 11 \\
\text { magic tales, } 7 \text { animal tales, and } 2 \text { factual }(3,200 \\
\text { clauses) }\end{array}$ & Stegen (2011) \\
\hline Bena & $\begin{array}{l}\text { [bez] G63 } \\
\text { Tanzania }\end{array}$ & $\begin{array}{l}6 \text { texts: } 3 \text { written and } 3 \text { lightly edited oral texts; } 4 \\
\text { fictional and } 2 \text { factual ( } 674 \text { clauses) }\end{array}$ & $\begin{array}{l}\text { Broomhall }(2011)^{*} \\
\text { Eaton (In press a) }\end{array}$ \\
\hline Malila & $\begin{array}{l}{[\mathrm{mgq}] \mathrm{M} 24} \\
\text { Tanzania }\end{array}$ & $\begin{array}{l}10 \text { lightly edited oral texts and } 4 \text { written texts: } 10 \\
\text { fictional and } 4 \text { factual ( } 755 \text { clauses) }\end{array}$ & Eaton (In press b)* \\
\hline Makonde & $\begin{array}{l}{[\mathrm{kde}] \mathrm{P} 23} \\
\text { Mozambique }\end{array}$ & $\begin{array}{l}8 \text { lightly edited oral texts: } 5 \text { fictional and } 3 \text { factual } \\
\text { ( } 585 \text { clauses) }\end{array}$ & Leach (In press)* \\
\hline
\end{tabular}

2.2 Forms of the three main demonstrative series. Each of the languages in this study has at least 3 demonstrative 'series', commonly referred to in Bantu grammatical descriptions as

2 In examples from Jita and Kwaya, the symbol /:/ at the start of a verb indicates far past tense and the symbol $/ \wedge /$ at the start of a verb indicates narrative tense with 3SG subjects. This is because the past anterior and the far past, and the 3SG form of the narrative and the 1SG form of the anterior are only distinguished through tone, which is not marked in the orthography, so these symbols are used to differentiate the forms.

3 Languages are classified using the ISO 639-3 language code as cited in Ethnologue (Lewis, Simons \& Fennig 2013) and Maho's (2003) updated version of Guthrie's classification of the Bantu languages.

4 Oral texts in all languages were lightly edited to remove performance errors, including false starts, whilst retaining features such as repetition which are characteristic of the medium. 
'proximal', 'referential', and 'distal'. ${ }^{5}$ In spatial-deictic (exophoric) use, the proximal demonstrative refers to an entity that is near to both the speaker and the addressee, the referential demonstrative typically refers either to an entity that is near to the addressee but further from the speaker or to an entity that is contrasted with something referred to by a proximal demonstrative, and the distal demonstrative refers to an entity that is far from both the speaker and the addressee.

In narratives, these same forms occur with different functions (outside of direct speech) that do not concern spatial deixis in the real world of the narrator and the audience. However we shall retain the labels 'proximal' [+, 'referential' [REF] and 'distal' [DIST] to refer to cognate demonstrative forms in different languages.

The proximal demonstrative series takes one of two forms in the languages surveyed here: in Fuliiru, Rangi, Bena, Malila and Makonde, it is formed by prefixing the vowel of the noun class prefix to the CV noun class prefix (e.g. Bena $u y u$ class 1 , ava class 2$){ }^{6}$ in Jita, Kabwa, Kwaya and Suba-Simbiti the proximal demonstrative is formed by prefixing the noun class prefix to $n u$ or $n o$ (e.g. Suba-Simbiti ono class 1, Jita bhanu class 2). ${ }^{7}$ The referential demonstrative in all languages is formed by prefixing the noun class prefix to the root $o$ or yo (e.g. Fuliiru uyo class 1, Rangi avo class 2). The distal demonstrative is formed by prefixing the noun class prefix to the root rya, $r a$ or la (e.g. Kwaya urya class 1, Rangi vara class 2, Malila zta class 1). Digo has variants of all three series, and is irregular in classes 1 and 2 (human singular and plural respectively); the 'basic' class 1 and 2 forms in Digo are hiyu/hinya (proximal), hiye/hinyo (referential) and yuya/hara (distal).

\section{Discourse analytic notions relevant to narrative texts}

Throughout this paper, mention will be made of different kinds of participants and different kinds of episodes. This section provides an overview of those aspects of participant reference and narrative macrostructure that are directly relevant to this study. For comprehensive introductions to narrative discourse analysis, see Grimes (1975), Dooley \& Levinsohn (2001), Levinsohn (2003), Longacre (1996) and Longacre \& Hwang (2012).

3.1 Participants. A defining characteristic of a narrative text is that it is structured around the activity of one or more participants, that is, characters who play some kind of active role in the story. Participants need to be introduced into the narrative, and then referred to subsequently (or "tracked") as the narrative develops. Typically participants are individuals, although the term can

5 See for example Ashton (1947:327). The term 'referential' is used because of the anaphoric function of this form in many Bantu languages to refer to previously mentioned entities and because the root of this demonstrative series is the so-called 'O of reference' (Ashton 1947:159). Occasionally 'referential' forms are termed 'non-proximal' or 'middle'. For further discussion of classifications of Bantu demonstratives, see Nicolle (2012:194-6).

6 Malila and Makonde are slightly irregular: Malila has $\boldsymbol{t} \boldsymbol{t} \boldsymbol{t}$ in classes 1 and 3, and Makonde has aju in class 1 .

7 Originally the two forms of the proximal demonstrative were distinct series, with the $n u / n o$ form referring to things that are very close to (i.e. touching) the speaker. Some languages have retained four demonstrative series, such as Fuliiru where the no form indicates proximity plus contrast, and Digo in which it no longer has a contrastive spatial-deictic use (see Nicolle 2012); we will not be concerned with this fourth series here. 
also refer to groups acting in unison. A primary distinction is made between major and minor participants.

Major participants typically receive some specific introduction and "are active for a large part of the narrative and play leading roles" (Dooley \& Levinsohn 2001:119). In some narratives major participants perform the roles of protagonist (the character who initiates most of the action) and antagonist (the character who is impacted by and reacts to the events initiated by the protagonist). In other narratives, it is not possible to distinguish a protagonist and an antagonist, but one major participant may be more important than others in terms of story development; this participant is referred to as the" primary major participant" 8 and the other major participants as "secondary major participants".

Minor participants are usually present only for short periods and play a more passive role; they are often referred to for the first time without any specific introduction, for example, as objects of a verb. Finally, props are entirely passive participants (either characters or objects) which do not play an active role in the story (Grimes 1975:43ff).

When there is continuity in a text, specifically when the same participants continue in the same grammatical roles from clause to clause, and there is no abrupt change of scene (that is, no change of thematic unit such as would often be represented by a paragraph break in modern written texts), participants can be referred to using a minimal amount of coding material. In eastern Bantu languages, this is typically achieved through the use of verbal affixes (subject and object concords ${ }^{9}$ prefixed to the verb) to refer to participants. When there is some discontinuity in a text, or when there is potential ambiguity regarding the intended referent, more explicit coding is required. In the eastern Bantu languages surveyed here, when there is a change of subject, or when a subject is repeated at the start of a new thematic unit, it is typically referred to using a proper name or a descriptive noun phrase.

The choice of whether a name or a descriptive noun phrase is used depends largely on the kinds of participants in a text. Some of the texts concern the activities of two or more animal characters (often a protagonist and an antagonist), and these texts tend to use the animals' names rather than descriptive noun phrases. For example, in the Jita text 'Watermelon' (70 clauses) in which Hare eats Hyena's watermelons and escapes from the trap that Hyena sets, 27 out of 29 subject NPs are the names Mtuuju 'Hare' and Wamembe 'Hyena' and only 2 are descriptive noun phrases. Similarly, in the Bena text 'Dog and Leopard' (152 clauses) 25 out of 34 subject NPs are the names $U$-Mbwa 'Dog' and U-Duuma 'Leopard', 5 are descriptive noun phrases, and 1 is a demonstrative.

Where narratives involve human participants, there is greater variation, perhaps because it is rare for all participants to be named. In the Jita text 'Mariro' (113 clauses) the primary major participant, Mariro, is referred to in subject position by name 16 times and twice as omukaruka oyo 'old.man that [REF]' whilst the secondary major participant, a group of cannibalistic women, is referred to 8 times using a descriptive noun phrase abhagasi bharya 'women those [DIST]' or abhagasi abho 'women those [REF]'. Even when a character has been named, it may still be referred to using a descriptive noun phrase. In the Digo text 'Mbodze and Matsozi' (70 clauses)

8 The primary major participant corresponds to the 'thematic participant' (Grimes 1975) and the 'global VIP' (Very Important Participant) (Dooley \& Levinsohn 2001).

9 Subject concords (also called 'subject markers') agree in terms of person/number or noun class with the subject and are obligatory in most tense and aspect forms; object concords (or 'object markers') are optional (see Bearth 2003:122-6 for an overview). 
the primary major participants, Mbodze and Matsozi, are referred to in subject position twice by name, once as asichana hinya 'girls these [PROX]' and once as hara asichana, Mbodze na Matsozi 'those [DIST] girls, Mboze and Matsozi'. The secondary major participant is a ghost, who is referred to in subject position 5 times, each time as zimu 'ghost' (or 'the ghost' as eastern Bantu languages do not have definite or indefinite articles).

When a participant is referred to using a descriptive noun phrase, especially when the participant is a human rather than an animal or spirit, it is common to find a demonstrative used attributively, as in abhantz bhaala 'people those [DIST]' and umuntu tzla 'person that [DIST]' in Malila. The proportion of descriptive noun phrases with and without attributive demonstratives varies between the languages in the survey, but also varies from text to text; however, attributive demonstratives are notable in all the text corpora. For example, in the Digo corpus of 864 clauses, 91 subject NPs contained a demonstrative and 76 did not; in addition there were 5 occurrences of demonstratives used predicatively, i.e., alone.

Although the eastern Bantu languages surveyed here have a range of other independent pronominal forms (that is, excluding verbal affixes), these occur far less frequently than demonstratives, usually for emphasis or contrast. For example, the Digo text corpus contained a total of 147 third person demonstratives (not restricted to subject position) compared to just 29 third person independent pronominal forms.

The use of demonstratives in referring expressions is the focus of this paper, but before their functions can be described, we will introduce another discourse-related concept: episodes.

3.2 Episodes. Episodes are divisions within a text which are determined by the content of the narrative itself rather than by any particular formal properties (although episodes may have formal correlates in any given language); that is, each episode serves a distinct purpose within the narrative as a whole and is defined by this purpose (see below). Episodes are distinct from paragraphs, in that the purpose of paragraphs is to help the hearer or reader process the text by grouping thematically related information together. A paragraph in a narrative text will typically exhibit continuity of participants, time and 'action' (event reporting, speech/thought reporting, or non-event material). Episode boundaries and paragraph boundaries may coincide, but they need not. In a very short story, a single paragraph may contain more than one episode; conversely, in a longer story one episode may consist of a number of paragraphs.

Structurally, narratives can be divided into two (very broad) types: climactic and episodic. The majority of texts in all of the languages included in this study were climactic. Climactic narratives often have a structure consisting of all or most of the following types of episode: ${ }^{10}$

- Orientation section (or introduction) which contains information such as the time and place in which the story takes place, and in which at least one major participant is introduced; the story theme may also be presented here (for example, 'There was once a young man who wanted to get married' would suggest that the theme of the story is 'how the young man finds a wife').

- Inciting episode (or complicating action) which presents the problem, conflict, or other situation upon which the story hinges; this is usually the point at which the event line starts.

10 This division is assumed to be universal, and is based on Longacre (1996:33-38), who in turn refers to Thrall, Hibbard \& Holman (1961), although as Longacre (1996:34) notes, "the antecedent tradition goes back to classic times.” For a slightly different classification, see Labov \& Waletzky (1967). 
- Developmental episodes which develop the situation introduced in the inciting episode and move towards a resolution. (The final developmental episode before the peak may be termed the pre-peak episode.)

- Peak episode in which the complication introduced in the inciting episode and developed in the developmental episodes reaches a climax; the peak may describe the resolution of the problem or tension that has developed, but it may equally be the point at which the problem or tension reaches a state in which no resolution is possible.

- Denouement (also called the post-peak episode or resolution) which contains fairly predictable material either describing events which happen after the peak or summarising the main events of the story.

- Conclusion (or coda) which brings the story to a close, for example by presenting the narrator's perspective on the story or summarizing the outcome of the story; a formulaic ending may also be used.

Episodic narratives often include an orientation section, inciting episode, denouement, and conclusion. But rather than a series of developmental episodes moving towards a peak; episodic narratives consist of a series of episodes with parallel structures and subject matter (that is, each episode is a token of a certain type). Each such episode may contain tension or a climax, but it need not, and some episodes - in particular towards the end of the narrative - may be more important than others.

\section{Functions of Demonstratives}

Cross-linguistically, demonstratives function at a number of different levels. A basic distinction is between exophoric (spatial-deictic) uses in which demonstratives refer to entities in the physical environment, and endophoric uses of demonstratives to refer to entities - including non-concrete entities such as propositions and events - that have already been mentioned. Various subcategories of endophoric use have been proposed, as well as additional uses associated with emphatic or emotional deixis (see Nicolle 2012:197-8 for a summary). However, in this paper we will be solely concerned with discourse-level functions of demonstratives in narrative texts, rather than with attempting to classify or describe the entire range of functions involving demonstratives.

It should also be noted that the discourse-level functions described in this paper are not intended to constitute an addition to the list of pragmatic functions associated with deixis, such as anaphora, discourse deixis, impure textual deixis, and emphatic deixis discussed, for example, in Levinson (1983: 61-68, 81, 85-7). Such pragmatic functions are associated contingently with individual occurrences of demonstratives in certain utterances, whereas the discourse-level functions of demonstratives which we will discuss below are associated systematically with all or most uses of a particular demonstrative form in a given text. In addition, rather than being byproducts of general communicative principles, the discourse-level functions of demonstratives in narrative texts are language-specific and therefore governed by convention.

When demonstratives are used in narrative texts, they may function in ways which are not (directly) related to any spatial-deictic use. Cross-linguistically, Himmelmann (1996) distinguishes four (non-spatial deictic) uses of demonstratives in narratives, which he terms 'situational', 'discourse deictic', 'recognitional' and 'tracking'. I will briefly describe these here, to distinguish them from the discourse-level functions of demonstratives that are the focus of this paper. 
Situational use establishes a referent relative to the situation in which the narrative is being related; for example, one Makonde text starts by situating the story during ing 'ondo ailá itandi 'that first war', where the distal demonstrative ailá situates the war (ing'ondo) relative to the time that the story was told:

\begin{tabular}{|c|c|c|c|c|c|c|}
\hline Ngulota & \multicolumn{2}{|c|}{ ku-va-langanga } & \multicolumn{2}{|c|}{ apa-ing'ondo. } & & \\
\hline 1SG.want & INF-2PL-tell & 6.story & 16.LOC & -9. war & & \\
\hline Maimyo & ala & apaing'ondo & ni & ing' ondo & ailá & itandi, \\
\hline 6.story & 6.DEM_PROX & 16.LOC-war & $\mathrm{COP}$ & 9.war & 9.DEM_DIST & 9.first \\
\hline itandéke & akuno & Mo & nbiki & yavyaka & kumi. & \\
\hline 9.happene & 16.here & Mozan & nbique & of.years & ten & \\
\hline
\end{tabular}

'I want to tell a story about something that happened during the war. This story took place at the time of that (DIST) first war here in Mozambique - the ten-year war.'

Discourse deictic use refers to the use of demonstratives to refer to propositions and events. In Digo, the class 8 referential demonstrative hivyo has this function:

$\begin{array}{lllllll}\text { Pho-fika } & \text { dziloni, } & \text { mbuzi } & \text { na } & \text { ng'ombe } & \text { z-a-uya } & \text { machaye. } \\ \text { 16.REL-arrive } & \text { evening } & \text { 10.goats } & \text { COM } & 10 . c o w s & 10 \text {-PST-return } & \text { alone }\end{array}$

A-ri-pho-ona hivyo, a-piga mbiru a-chi-iha atu osi 3SG-PST-16.REL-see 8.DEM_REF 3SG-hit 9.horn 3PL-CONS-call 2.people 2.all

'When evening arrived, the goats and cows returned on their own. When they saw that (REF), they blew a horn and called all the people...'

Recognitional use identifies a particular referent using shared knowledge that is not derived from situational clues or preceding discourse. Recognitional use is illustrated in the second sentence of the following extract from the start of a Digo narrative (Nicolle In press, 92); the man has not previously been mentioned, but he is referred to using a distal demonstrative yuya because shared cultural knowledge allows the addressee to assume that the woman in the first line has a husband. ${ }^{11}$

11 As one anonymous referee has observed, it is also possible that the narrator assumed that his audience was familiar with the particular story about to be told, and so the man is identifiable for that reason. In either case, the referent has not previously been mentioned. 
(3)

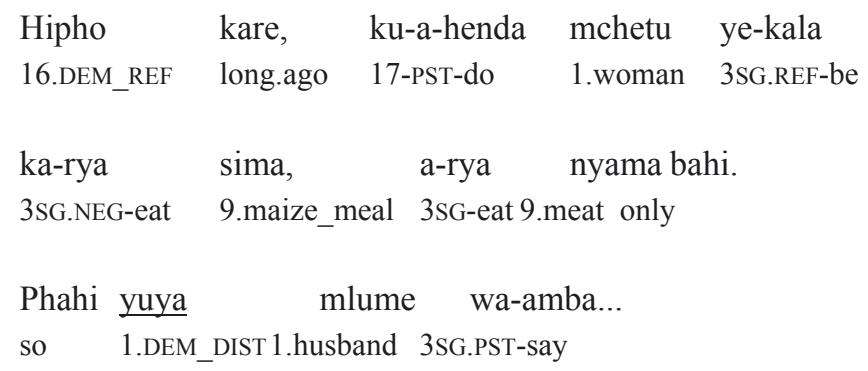

'Long ago there was a woman who wouldn't eat maize meal, but would only eat meat. So that (DIST) husband said...'

Finally, tracking use refers to the way demonstratives are used to help the addressee to keep track of what is happening to (usually major) participants in a narrative. This is a specific instance within the context of a narrative of the more general anaphoric use (Diessel 1999), in which demonstratives refer to entities which have been previously mentioned in the same discourse. Most occurrences of demonstratives in the eastern Bantu narrative texts discussed below in sections $4.1-4.4$ are of this kind. However, in addition to this basic tracking or anaphoric use, these demonstratives exhibit different discourse-level functions in different languages.

These discourse-level functions can be grouped into four sets or systems, which I will term for convenience 'activation status', 'agency', 'text structuring', and 'thematic development'. Each language exhibits one of these systems. The discourse-level functions described below were found in factual and fictional texts, and in both written and oral texts for all languages.

4.1 Activation status. In Jita, Kwaya, Kabwa, Suba-Simbiti, Malila, and possibly also in Rangi, the major discourse-level function of referential and distal demonstratives is to indicate the activation status ${ }^{12}$ of (major) participants. Masatu (In press) provides an operational definition of activation in Suba-Simbiti which applies to all of these languages:

a participant is considered to be activated in the mind of the listener if they have been explicitly mentioned in the previous event (which is not necessarily comprised of the previous clause or sentence alone) or if they are not mentioned but assumed to be an active participant in the action. [p.27]

In Jita, Kwaya, Kabwa and Malila, a major participant which is reactivated after a period of inactivity is always referred to using a NP plus a distal demonstrative. ${ }^{13}$ In the following Kwaya example (Odom In press, 22), the participant (who is described as 'that relative') is reintroduced to the narrative after an absence of ten sentences using a NP plus distal demonstrative.

12 The term 'activation status' is used in the sense of Chafe $(1976$; 1994) to refer to the cognitive status of information in working memory.

13 Rundell (2012: 81-88) reports the same strategy for Ngoreme [ngq] and Ikizu [ikz]. 
(4) :E-e-j-ire oku-remera bha-chaa-ri,

3SG-P3-come-P3INF.refuse 3PL-PERS-COP

waamuwaabho $\underline{\text { urya }} \wedge$ n-aa-bha-rora

relative.POSS.3SG 1.DEM_DIST NARR-3SG-3PL-see

'While she was still refusing, that (DIST) relative saw them...'

In the following Malila example (Eaton In press, 15), the participants are reactivated after a digression about wild animals that lived in the area where the events took place.

$\begin{array}{llccc}\begin{array}{l}\text { Basi } \\ \text { well }\end{array} & \text { 2.phantu } & \underline{\text { bhaala }} & \text { i-kha-biidi } & \text { bha-piny-e } \\ \text { 2.DEM_DIST 9-NARR-be_necessary } & \text { 3PL-tie-SUB }\end{array}$

'Well, those (DIST) people, it was necessary that they should tie that (DIST) person to the stretcher.'

In Jita and Kwaya, when a major participant is activated and is referred to using a NP rather than just a subject prefix, a referential demonstrative is almost always used, ${ }^{14}$ as in the following example from Jita (Pyle \& Robinson In press, 28).

(6) ...abhaanu abharebhe mubhanu :bhaasigaaye kwigogo :bhaariga nibhamenya okuwuga.

Abhawugi abho bha-a-sakir-aga abheejabho...

2.swimmers 2.DEM_REF 3PL-P3-help-IPFV 2.their_fellows

'...some of the people among those who remained on the log knew how to swim. Those (REF) swimmers were helping their fellows...'

This does not apply to Kabwa and Malila, where activated participants are referred to by both referential and distal demonstratives in roughly equal measure.

The situation in Suba-Simbiti and Rangi is less clearcut. In the Suba-Simbiti text corpus, of reactivated participants, 21 were referred to using distal demonstratives and 7 using referential demonstratives; of activated participants, 19 were referred to using referential demonstratives and 6 using distal demonstratives. There was thus a tendency rather than an absolute requirement for reactivated participants to be referred to using distal demonstratives, and for activated participants to be referred to using referential demonstratives.

In Rangi, distal demonstratives are more frequent than referential demonstratives in the text corpus, but there is considerable variation between texts and even within texts (Stegen 2011:261). This variation notwithstanding, Stegen (2011:262) comments: "While there are no hard and fast

14 This does not apply to objects in Kwaya, as discussed below. 
rules, as exceptions can be found to any regularities, $t w o$ [referential] tends to be used to reactivate a major participant after an episode involving other participants, whereas ura [distal] tends to be used to continue the active status of a major participant." If this is correct, the functions of referential and distal demonstratives are reversed relative to their cognates in Jita, Kwaya, Kabwa, Malila and Suba-Simbiti; however, the present author has noted numerous exceptions to these proposed generalizations in Rangi.

The generalizations discussed so far apply to participants functioning as subjects. However, in Malila, of 10 major and minor participants functioning as objects (whether post-verbal or preverbal, but excluding those in direct speech) nine are referred to using distal demonstratives, even if the participant is still activated. There is evidence that objects that are already activated may sometimes be referred to using distal demonstratives in Kwaya also; of 13 major and minor participants functioning as objects (excluding in direct speech), 7 are referred to using referential demonstratives, 5 (all activated) using distal demonstratives, and 1 using a proximal demonstrative. The following Kwaya example (Odom In press, 24) illustrates the use of a distal demonstrative with an object that is activated.

$$
\begin{aligned}
& { }^{\wedge} \text { n-aa-nyoora abhayeesi. Abhayeesi bharya ka-a-bha-bhwira ati } \\
& \text { NARR-3SG-meet 2.blacksmiths 2.blacksmiths 2.DEM_DISTPRES-3SG-3PL-tell that } \\
& \text { '...he met some blacksmiths. Those (DIST) blacksmiths, he told them that...' }
\end{aligned}
$$

There is no evidence that objects are systematically referred to using distal demonstratives in the Jita, Kabwa, Suba-Simbiti and Rangi texts.

Proximal demonstratives occur rarely in narrative texts outside of direct speech in these six languages. Owing to the rarity of proximal demonstratives, any hypothesis concerning their functions will have to be corroborated using data from much larger corpora than are currently available. However, the rarity of proximal demonstratives suggests that when they are used, their use serves a particular purpose. In the following Kwaya example (Odom In press, 25), a servant has tricked her mistress into swapping clothes; their host thinks that the mistress is the servant and the servant is the mistress, so he makes the mistress work hard while the servant relaxes in the house. It is possible that the servant is referred to using a proximal demonstrative because the situations described are simultaneous rather than sequential (so the event line of the narrative is disrupted) and/or because the situations are in contrast.

$$
\begin{aligned}
& \text { m-ba-mu-yaan-aga mirimu emisito. Unu omugaya owa } \\
& \text { NARR-3PL-3SG-give-HAB4.work 4.hard 1.DEM_PROX 1.servant 1.ASS } \\
& \text { omwenda gwa ekisi } \wedge^{n} \text {-aa-sigara }{ }^{\wedge} \text { n-aa-rya ebhiinu iika. } \\
& \text { 3.cloth 3.ASS 7.fine NARR-3SG-remain NARR-3SG-eat 7.thing 9.house }
\end{aligned}
$$

'...then they were giving her hard labor. This (PROX) servant of the nice clothes then remained, eating things at the house.'

In Kwaya (Odom In press, 24), the discourse functions of demonstratives described above may break down during the peak episode, or from the peak episode on. For example, in one text (labeled H1 in the text corpus) there are no demonstratives apart from locative forms during and 
after the peak episode, whereas in another text (H2) distal demonstratives are used to refer to activated major participants after the peak episode.

4.2 Agency. In Bena, demonstratives are used to distinguish participants who function semantically as agents (participants who intentionally initiate some action) from those which play a more passive role, such as patients and experiencers (who do not initiate or control an action that affects them). Distal demonstratives are used to refer to both major and minor participants, whether they remain activated or are reactivated (in the sense described in section 4.1 above), so long as they play an agent-like role on the event line. ${ }^{15}$ Referential demonstratives refer to participants with non-agent roles, such as experiencer and patient.

The use of distal and referential demonstratives is illustrated in the first two sentences of the example below (Broomhall 2011), in which the farmer and the child function as agents and are referred to using distal demonstratives. The use of the distal demonstrative is not linked to activation status in Bena: the farmer has been absent from the narrative for the previous two sentences, and is reactivated here; the child is referred to as the object in the first sentence, and is therefore already activated. In the following sentence, the bird is referred to using a referential demonstrative since it is an experiencer rather than an agent. In the final sentence, both the child and the bird are agents and are referred to using distal demonstratives.

(9) Umunya mugunda yula akumutumaga umwana vakwe akalole umuhadiko gula. Umwana yula ihelelaga, iwonaga ilidege ilivaha ligwiliye. Ilidege ilyo lyavye likumuwona litigilaga, "Ndinyilika undzawule na yuuve ndilakwawula kigono." Umwana yula akulyawulaga, lildege lila lipulundukaga lihelelaga.

'That (DIST) farmer sent his child to check on that (DIST) trap. That (DIST) child went, and he found the large bird caught. That (REF) bird when it saw him it said, "I beg you to free me and one day I will help you." That (DIST) child freed it, that (DIST) bird flew up and went away.'

All of the participants in the example above are subjects, so the use of a referential demonstrative in the first reference to the bird is not determined by syntactic role. However, since participants in object position and in complement clauses are typically patients rather than agents, they are usually referred to with referential demonstratives in Bena. (Note that this is different from Kwaya and Malila, where participants in object position are typically referred to using distal demonstratives.) Nonetheless, the determining factor is agentivity rather than syntactic role.

In the Bena corpus of 6 narrative texts (674 clauses) distal demonstratives are used 17 times to refer to participants functioning as agents, with verbs meaning 'set a trap', 'send', 'go', 'untie', 'fly', 'return', 'answer', 'climb', 'deny', 'stay', 'come', 'leave', 'make noise', 'get up' and 'be deceitful'. There are, however, two uses of distal demonstratives with non-agentive subjects;

15 The event line is the series of events exhibiting contingent temporal succession which are presented in iconic temporal order that corresponds to what Labov \& Waletzky (1967) term 'foreground' material. Non-event line clauses, such as those describing pre-existing situations, flashbacks, motivations for a participant's actions and so forth, therefore correspond to 'background' material. I have avoided the terms 'foreground' and 'background', however, since they are defined in various different ways (see for example Fleischmann 1985; Grimes 1975; Hopper 1979; Hopper \& Thompson 1980; Reinhart 1984). For an alternative approach in which foreground and background are treated as epiphenomena resulting from the way narratives are processed, see Unger (2002). 
Umwana yula asaawesaga ukwinuka nambi ukwika ('Child that [DIST] was not able to climb or descend') and Umwana yula ikwiwukuga ('Child that [DIST] remembered').

Referential demonstratives are used 9 times to refer to participants with non-agent semantic roles, with verbs meaning 'see', 'get fat', 'agree' and 'refuse'. Five of these referential demonstratives occur in one story in which Spider and Hare compete to woo a girl. The girl is never an agent (she only reacts to the advances of Spider and Hare or is the object of a verb), and is consistently referred to as muhindza uyo ('girl that [REF]').

Proximal demonstratives in Bena are only found in non-event line clauses. The following example (Eaton In press, 75) illustrates this:

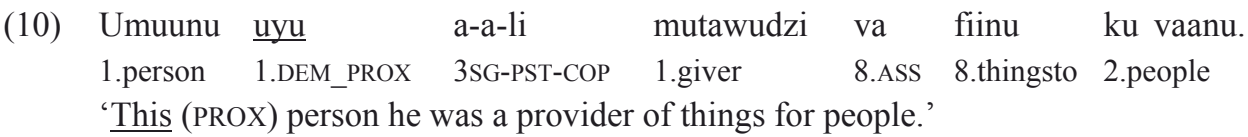

In one example (Broomhall 2011), a referential demonstrative is also used in non-event line material. The phrase avatavangu ava ('these enemies') contains the class 2 (animate plural) proximal demonstrative ava, and the phrase avatavangu vaavo ('those enemies') contains the class 2 referential demonstrative vaavo; the enemies referred to are the same in both phrases.

(11) ...pakuva alukagwe ukutigila avatavangu vali biihi mu luvala lwanavo. Kangi alukagwe ukuta avatavangu ava vaviifu hiilo. Alukagwe nu lwitigila avatavangu vaavo viigalula avaanu pamwinga...

'...because he knew that enemies were near their area. Moreover, he knew that these enemies (PROX) were very bad. He knew that those enemies (REF) take people hostage...'

4.3 Text structuring. Digo narratives also make use of distal, referential and proximal demonstratives, but the discourse functions of these demonstratives are different from those of the languages described previously. In Digo, different demonstratives are used to indicate the start and occasionally the end of the main event line, and to distinguish major and minor participants. I have grouped these functions together under the general label 'text structuring'.

In Digo, different episodes are characterized by the presence of different demonstratives. The orientation section often serves simply to introduce the major participant(s), but when additional information is provided about a major participant which has just been introduced, a referential demonstrative is used:

(12) Chisha pha-chi-kala na mjeni pha=pho lalo-ni. then 16-CONS-be COM 1.stranger 16=16.RM locality-LOC

Mjeni hiye kala ka-many-wa a-ri-vyo...

1.stranger 1.DEM_REF PST 3SG.NEG-know-PAS 3SG-COP-8.REL

'Now there was a stranger there at their place. No-one knew much about that (REF) stranger...' [literally: That stranger was not known how he was] (Nicolle In press, 71) 
The inciting episode is characterized by the use of either proximal demonstratives or distal demonstratives to refer to major participants. Outside of direct speech, proximal demonstratives are very rare in Digo texts, and the inciting episode is often the only place in a given text where a proximal demonstrative is found. The following example (ibid. 66) illustrates this use.

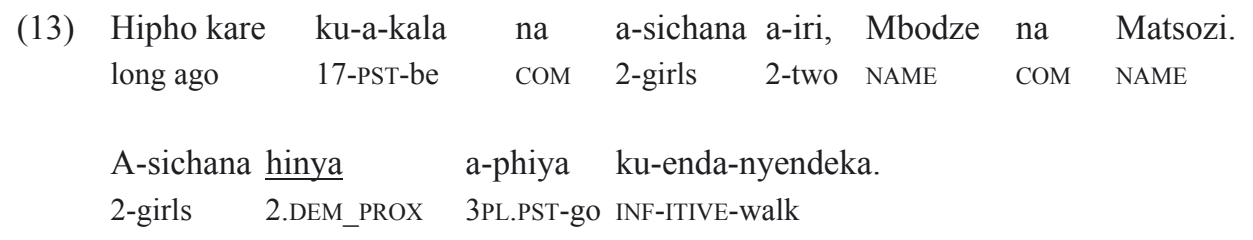

'Long ago there lived two girls, Mbodze and Matsozi. These (PROX) girls went to go for a walk.'

The bulk of most narratives consists of developmental episodes and the peak episode. Major participants in Digo are typically referred to throughout the developmental and peak episodes with distal demonstratives, regardless of whether the participants are activated or reactivated, agents or non-agents. In the 7 texts used in Nicolle (In press), distal demonstratives are used to refer to major participants in developmental and peak episodes 64 times, whereas referential demonstratives are used 5 times and proximal demonstratives 3 times (twice in non-event line material).

In some texts, distal demonstratives are used more frequently for the protagonist or primary major participant than for the antagonist or secondary major participant (see section 3.1). In such texts, the antagonist or secondary major participant is referred to more often using a name or descriptive noun phrase without any demonstrative. Minor participants in all Digo texts are usually referred to using descriptive noun phrases without demonstratives.

The denouement (or resolution) is often no different from the developmental episodes in terms of participant reference, but in some texts major participants are referred to using referential demonstratives in the denouement. In the following example (ibid. 65), the woman (the protagonist) is referred to with a referential demonstrative, and the old man (a secondary major participant) with a distal demonstrative.

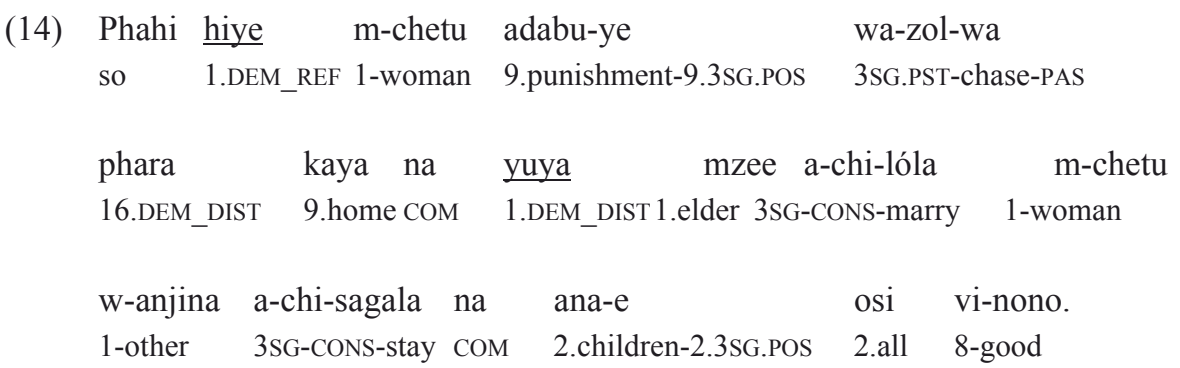

'So that (REF) woman her punishment, she was chased away from her home, and that (DIST) old man married another woman and they lived happily with both of his children.' 
Makonde also uses demonstratives for text structuring purposes. The proximal demonstrative in Makonde is most frequently used in the orientation section immediately after the introduction of a participant, as in the example below (Leach In press, 60). Note that this is in contrast to Digo, where the referential demonstrative is commonly used in such situations.

$\begin{array}{llllll}\text { A-ndí-pagwa } & \text { munu, } & \text { munu } & \text { aju } & \text { madengo } & \text { ake } \\ \text { 3sG-PST-be } & \text { 1.person } & \text { 1.person } & \text { 1.DEM_PROX } & \text { 6.work } & \text { 6.3sG.POS }\end{array}$

ku-vele kwaka dyomba.

NARR-COP INF.hunt 10.fish

'There was a person, this (PROX) person, his work was to catch fish.'

Makonde has a 'continued reference' demonstrative, which is a short form of the referential demonstrative (which is itself extremely rare). This is used to maintain reference to minor participants and props. The distal demonstrative in Makonde is the most frequent; it is also used to refer to minor participants and props, and less frequently refers to major participants. With minor participants and props, the distal demonstrative indicates that they are temporarily salient, and with major participants, it marks key developments in the narrative (including, but not restricted to, the peak episode). This is illustrated in the following example (Leach In press, 62), where a mother runs back into an enemy-occupied village to rescue a child who has been left behind.

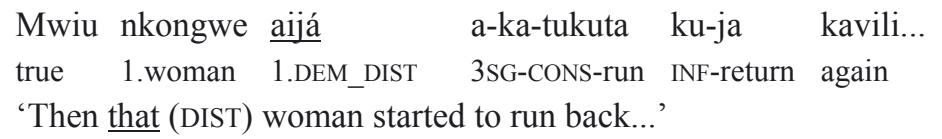

Demonstratives in Makonde are therefore used both to structure the text and to indicate important developments. Marking developments in a story is the primary function of demonstratives in Fuliiru, to which we turn next.

4.4 Thematic development. In addition to the basic tracking use which is common to demonstratives in all the languages in the sample, referential and distal demonstratives in Fuliiru serve to indicate important developments in narrative texts. That is, demonstratives in Fuliiru function as 'thematic development markers ${ }^{16}$ marking significant events that lead from the initial problem (which is typically introduced in the inciting episode), to the story's culmination (in the peak episode). Proximal demonstratives are extremely rare in the Fuliiru text corpus, and are absent from most texts.

The inciting episode of most texts contains a referential demonstrative. Thereafter, in some Fuliiru texts, subsequent referential demonstratives indicate 'default' or regular developments

16 Thematic development markers "indicate that the material so marked represents a new development in the story or argument, as far as the author's purpose is concerned." (Dooley \& Levinsohn 2001: 93) They are also termed 'developmental markers' (ibid.) and 'thematic salience markers' (Van Otterloo 2011: 447). Conjunctions, redundant references to subjects (Levinsohn 2000: 72), locative markers (Van Otterloo 2011: 467-8) and demonstratives have all been shown to function as thematic development markers in different languages. 
towards the culmination, whilst distal demonstratives indicate 'major' developments (Van Otterloo 2011: 447-8).

Some texts make no use of distal demonstratives at all, and other texts do not use referential demonstratives at all, outside of the inciting episode ${ }^{17}$ in such texts, whichever demonstrative is used seems to indicate thematic developments regardless of the distinction between regular and major developments.

Table 2 presents the major events in one Fuliiru narrative (Van Otterloo In press, 18-20). All the phrases containing a demonstrative are listed, and those with distal demonstratives indicating major thematic developments are highlighted. Although Van Otterloo (2011: 448) recognizes that the decision as to when to use a thematic development marker and which one to choose is a subjective matter, it can be seen from Table 2 that the phrases containing a demonstrative provide a fairly complete synopsis of the story up to the peak episode.

Unless otherwise stated, phrases containing demonstratives in Table 2 are in subject position. However, the syntactic role of the demonstrative-marked participant, and indeed the identity of the participant, does not appear to be crucial; in fact, in line 7 the demonstrative refers to an event rather than a participant. It is the mere presence of a referential or distal demonstrative somewhere in the sentence that indicates a thematic development.

The default thematic development markers (referential demonstratives) tend to occur towards the beginning of the story, and major thematic development markers (distal demonstratives) only occur in the second half of the text. The culmination of the story occurs when the old man opens the door and allows the lion to enter the room where the cow is hiding. After this point, there are no more demonstratives functioning as thematic development markers since the story has reached its climax, and all further events are predictable (the lion enters the room and kills the cow).

17 Van Otterloo (2011: 447) states that in "formal" texts, only referential demonstratives, indicating 'default' developments occur; he does not discuss texts in which only distal demonstratives occur after the inciting episode. 
Table 2: Demonstratives functioning as thematic development markers

Line Summary of main events

2 Lion and cow became friends

6 Their children were playing

$7 \quad$ Cow's child accidentally kills lion's child

11-13 Cow sees child dead, runs away, and asks an old man for protection

14 Old man asks why he should hide cow

16 Old man hides cow and its child

17 Old man tells cow the rooster will crow when lion arrives

18 Lion finds dead child and suspects cow

22 Lion meets old man

23 Lion asks old man where cow is

$24 \quad$ Rooster crows

25 When rooster crows, cow realizes danger

27 Lion returns to old man and asks about cow

28 Old man stalls for time

29 Old man warns cow that lion is outside

30-32 After some days, cow's child dies of hunger and lion hears cow crying

33 Lion accuses old man of lying about cow

35 Old man denies harboring cow

$37 \quad$ Lion tells old man to open the door

38 Old man opens the door

39-42 Lion enters the room, argues with cow, and finally kills cow
Fuliiru

Uyo wandare na wangaavu

Yabo baana

Mu yukwo kushaata

Iyo ngaavu / uyo mwana

Uyo mushaaja

Uyo mushosi

Uyo mushosi

anahulukira ku'lya
mushaaja

ulya mushaaja

Lulya luhazi

Yulwo lukazi

Ulya mushaaja

Uyo mushaaja

Ulya mushaaja

uyo mushaaja

uyo mushaaja

ulya mushaaja

Ulya mushaaja
Demonstratives

That (REF) lion and cow

Those (REF) children

In that (REF) playing

That (REF) cow / that (REF) child

That (REF) old man

That (REF) man

That (REF) man

(no demonstrative)

she met that (DIST) old man (oblique)

that (DIST) old man (object)

That (DIST) rooster

That (REF) rooster

that (DIST) old man (oblique)

That (REF) old man

That (DIST) old man

(no demonstrative)

that (REF) old man (object)

That (REF) old man

that (DIST) old man (object)

that (DIST) old man

(no demonstrative)

\section{Summary}

Four discourse-level functions of demonstratives were distinguished in eastern Bantu narrative texts: activation status, agency, text structuring and thematic development. Each of the languages represented in the survey favors one of these functions, with the exception of Makonde, which exhibits both text structuring and thematic development. As more languages are investigated, it is possible that additional discourse-level functions will be discovered. These discourse-level functions are distinct from (though compatible with) Himmelmann's (1996) category of 'tracking 
use'. A key distinction in all four functions and in all of the languages in this study is made between distal demonstratives and referential demonstratives; proximal demonstratives play a much more restricted role.

Indicating the activation status of participants is the most common of the four narrative functions, and is found in Jita, Kwaya, Kabwa, Malila, Suba-Simbiti, and possibly also in Rangi. In Jita, Kwaya, Kabwa and Malila, referential demonstratives are used consistently to refer to participants which remain activated (mentioned or involved in the previous event). In Jita and Kwaya, distal demonstratives are used consistently to refer to participants which are reactivated after an absence. In Suba-Simbiti there is a tendency for referential demonstratives to refer to activated participants and for distal demonstratives to refer to reactivated participants, and in Rangi this tendency appears to be reversed. In Malila, and possibly also in Kwaya, most objects are referred to using distal demonstratives even when already activated.

Indicating whether participants are agents or non-agents is the primary narrative function of demonstratives in Bena. Distal demonstratives refer to participants that have an agent semantic role, and referential demonstratives refer to participants which are non-agents (such as experiencers and patients). Proximal demonstratives are only found in non-event line clauses.

Text structuring is a term which describes how demonstratives are used to distinguish different types of participant (protagonist, antagonist, major, minor, etc.) and to delimit different episodes (in particular the start and end of the main event line). In Digo, distal demonstratives refer to major participants, and in particular to protagonists and primary major participants, throughout the developmental episodes and the peak episode, and sometimes also in the inciting episode and the denouement (that is, throughout the episodes which contain the main event line). Referential demonstratives refer to major participants in the orientation section and the denouement (that is, in the episodes before the event line has begun and after the peak episode, which marks the culmination of the story). Proximal demonstratives are rare, but can refer to major participants in the inciting episode.

In Makonde, proximal demonstratives are found in the orientation section, and referential demonstratives are used only for minor participants and props. Distal demonstratives, on the other hand, refer to both minor and major participants, but are only used to refer to major participants at places in the narrative where key thematic developments occur. This is an example of the thematic development function, which is most evident in Fuliiru narrative texts. In Fuliiru, referential and distal demonstratives function as thematic development markers. In most texts, referential demonstratives occur when there are regular developments leading towards the culmination of a story, and distal demonstratives occur when there are major developments (including the culmination itself). Not all Fuliiru texts distinguish these functions of referential and distal demonstratives, and sometimes one or the other is used throughout to indicate all thematic developments in a text.

The discourse-level functions of demonstratives in eastern Bantu languages are summarized in Table 3. 
Table 3: Discourse-level functions of demonstratives in eastern Bantu languages

\begin{tabular}{|c|c|c|c|}
\hline Language & Distal Demonstrative & Referential demonstrative & $\begin{array}{l}\text { Proximal } \\
\text { demonstrative }\end{array}$ \\
\hline $\begin{array}{l}\text { Jita, Kwaya, Kabwa, } \\
\text { Malila, Suba-Simbiti } \\
\text { (possibly reversed in } \\
\text { Rangi) }\end{array}$ & $\begin{array}{l}\text { Reactivated referent (Jita, } \\
\text { Kwaya; tendency in Suba- } \\
\text { Simbiti) } \\
\text { (Malila: most objects) }\end{array}$ & $\begin{array}{l}\text { Activated referent } \\
\text { (tendency in Suba- } \\
\text { Simbiti) }\end{array}$ & $\begin{array}{l}\text { Rare: possibly for } \\
\text { non-event line } \\
\text { material and/or } \\
\text { contrast }\end{array}$ \\
\hline Bena & Agent semantic role & Non-agent semantic role & $\begin{array}{l}\text { Non-event line } \\
\text { material }\end{array}$ \\
\hline Digo & $\begin{array}{l}\text { Major participants } \\
\text { (especially protagonists } \\
\text { and primary major } \\
\text { participants) in event line } \\
\text { clauses }\end{array}$ & $\begin{array}{l}\text { Major participants in the } \\
\text { orientation section and } \\
\text { the denouement }\end{array}$ & $\begin{array}{l}\text { Some major } \\
\text { participants in the } \\
\text { inciting episode and } \\
\text { some non-event line } \\
\text { material }\end{array}$ \\
\hline Makonde & $\begin{array}{l}\text { Temporarily salient minor } \\
\text { participants; key } \\
\text { developments with major } \\
\text { participants }\end{array}$ & $\begin{array}{l}\text { Continued reference to } \\
\text { minor participants and } \\
\text { props (using a short } \\
\text { form) }\end{array}$ & $\begin{array}{l}\text { Major participants in } \\
\text { the orientation section }\end{array}$ \\
\hline Fuliiru & $\begin{array}{l}\text { Major thematic } \\
\text { developments }\end{array}$ & $\begin{array}{l}\text { Regular thematic } \\
\text { developments }\end{array}$ & Extremely rare \\
\hline
\end{tabular}

Abbreviations Used

1., 2., etc. noun class 1 , noun class 2 , etc. IPFV imperfective

$\begin{array}{llll}\text { 1PL } & \text { first person singular } & \text { ITIVE } & \text { itive } \\ \text { 1SG } & \text { first person plural } & \text { LOC } & \text { locative } \\ \text { 2PL } & \text { second person plural } & \text { NARR } & \text { narrative tense } \\ \text { 2SG } & \text { second person singular } & \text { NEG } & \text { negative } \\ \text { 3PL } & \text { third person plural } & \text { P1 } & \text { near past } \\ \text { 3SG } & \text { third person plural } & \text { P3 } & \text { far (remote) past } \\ \text { ASS } & \text { associative marker } & \text { PAS } & \text { passive } \\ \text { COM } & \text { comitative marker } & \text { PERS } & \text { persistive } \\ \text { COP } & \text { copula } & \text { POSS } & \text { possessive } \\ \text { CONS } & \text { consecutive tense } & \text { PRES } & \text { present tense } \\ \text { DEM_DIST } & \text { distal demonstrative } & \text { PST } & \text { past } \\ \text { DEM_PROX } & \text { proximal demonstrative } & \text { REL } & \text { relative marker } \\ \text { DEM_REF } & \text { referential demonstrative } & \text { RM } & \text { referential marker } \\ \text { HAB } & \text { habitual } & \text { SUB } & \text { subjunctive } \\ \text { INF } & \text { infinitive } & & \end{array}$




\section{References}

Ashton, E. O. 1947. Swahili grammar. $2^{\text {nd }}$ edition. London: Longman.

Bearth, Thomas. 2003. Syntax. In Derek Nurse \& Gérard Philippson (eds.) The Bantu languages, 121-142. London and New York: Routledge.

Broomhall, Elizabeth. 2011. Bena text linguistics. Unpublished ms. Nairobi: Africa International University.

Chafe, Wallace L. 1976. Givenness, constrastiveness, definiteness, subjects, topics and point of view. In Charles N. Lee (ed.), Subject and Topic, 27-55. New York: Academic Press.

Chafe, Wallace L. 1994. Discourse, consciousness, and time: The flow and displacement of conscious experience in speaking and writing. Chicago: University of Chicago Press.

Diessel, Holger. 1999. 'The morphosyntax of demonstratives in synchrony and diachrony', Linguistic Typology 3:1-49.

Dooley, Robert A. \& Stephen H. Levinsohn. 2001. Analyzing discourse: A manual of basic concepts. Dallas: SIL International.

Eaton, Helen. In press a. Malila narrative discourse. To appear in SIL Language and Culture Documentation and Description. Dallas: SIL International.

Eaton, Helen. In press b. Bena narrative discourse. To appear in SIL Language and Culture Documentation and Description. Dallas: SIL International.

Fleischmann, Suzanne. 1985. Discourse functions of tense-aspect oppositions in narrative: toward a theory of grounding. Linguistics 23: 851-882.

Grimes, Joseph E. 1975. The thread of discourse. The Hague: Mouton.

Higgins, Holly. 2010. Discourse features of Kabwa and accompanying texts. Unpublished ms. Dar-es-Salaam: SIL Uganda-Tanzania Branch.

Himmelmann, Nikolaus P. 1996. Demonstratives in narrative discourse: A taxonomy of universal uses. In Barbara Fox (ed.), Studies in anaphora, 205-254. Amsterdam: John Benjamins.

Hopper, Paul J. 1979. Aspect and foregrounding in discourse. In Talmy Givón (ed.), Syntax and Semantics 12: Discourse and syntax, 213-241. San Diego and London: Academic Press.

Hopper, Paul J. \& Sandra A. Thompson. 1980. Transitivity in discourse. Language 56: 251-299.

Labov, William \& Waletzky, Joshua. 1967. Narrative analysis: Oral versions of personal experience. In June Helm (ed.), Essays on the verbal and visual arts, 12-44. Seattle: University of Washington Press.

Leech, Rhoda. In press. Makonde narrative discourse. To appear in SIL Language and Culture Documentation and Description. Dallas: SIL International.

Levinsohn, Stephen H. 2000. Discourse features of New Testament Greek: A coursebook on the information structure of New Testament Greek. $2^{\text {nd }}$ edition. Dallas: SIL International.

Levinsohn, Stephen H. 2003. Analysis of narrative texts. Dallas: SIL International.

Levinson, Steven. 1983. Pragmatics. Cambridge: Cambridge University Press.

Lewis, M. Paul, Gary F. Simons and Edward D. Fennig. 2013. Ethnologue: Languages of the world, seventeenth edition. Dallas, TX: SIL International. www.ethnologue.com

Longacre, Robert E. 1996. The grammar of discourse, $2^{\text {nd }}$ ed. New York \& London: Plenum Press.

Maho, Jouni. 2003. A classification of the Bantu languages: An update of Guthrie's referential system. In Derek Nurse \& Gérard Philippson (eds), The Bantu languages, 639-651. London and New York: Routledge. 
Masatu, Amanda. In press. Suba-Simbiti narrative discourse. To appear in SIL Language and Culture Documentation and Description. Dallas: SIL International.

Nicolle, Steve. 2012. Semantic-pragmatic change in Bantu -no demonstrative forms. Africana Linguistica 18: 193-233.

Nicolle, Steve. In press. Digo narrative discourse. To appear in SIL Language and Culture Documentation and Description. Dallas: SIL International.

Odom, Shannon Ronit. In press. Kwaya narrative discourse. To appear in SIL Language and Culture Documentation and Description. Dallas: SIL International.

Pyle, Allison and Holly Robinson. In press. Jita narrative discourse. To appear in SIL Language and Culture Documentation and Description. Dallas: SIL International.

Reinhart, Tanya. 1984. Principles of Gestalt perception in the temporal organization of narrative texts. Linguistics 22: 53-94.

Rundell, Oliver. 2012. A comparative discourse analysis of some Bantu languages in Tanzania. Unpublished MA dissertation: Middlesex University, London.

Stegen, Oliver. 2011. In quest of a vernacular writing style for the Rangi of Tanzania: Assumptions, processes, challenges. Edinburgh: University of Edinburgh $\mathrm{PhD}$ thesis. http://www.ethnologue.com/show_work.asp?id=928474542655 (8 October, 2012.)

Thrall, William F., Addison Hibbard \& C. Hugh Holman. 1961. A handbook to literature. New York: The Odyssey Press.

Unger, Christophe. 2002. Global coherence, narrative structure, and expectations of relevance. Paper presented at the Relevance Theory and Literature Conference, Huddersfield, UK, 12-13 September 2002.

Van Otterloo, Roger (2011). The Kifuliiru language, Vol.2: A descriptive grammar. Dallas: SIL International.

Van Otterloo, Roger. In press. Fuliiru narrative discourse. To appear in SIL Language and Culture Documentation and Description. Dallas: SIL International.

Steve Nicolle

SIL International

steve_nicolle@sil.org
Received: 23 September 2013

Accepted: 9 March 2014

Revisions: 12 June 2014 